\title{
Estudo epidemiológico dos fatores associados a utilização dos serviços odontológicos por adultos
}

\section{Daniela Naomi Miasiro*, Jamille Silva Nogueira, Antonio Carlos Pereira, Jaqueline Vilela Bulgareli}

\section{Resumo}

Trata-se de um estudo analítico transversal com dados secundários e de domínio público da Pesquisa Estadual de Saúde Bucal SB São Paulo 2015 feita em 163 municípios do Estado com a participação de 6051 adultos de 35-44 anos. As variáveis utilizadas no estudo foram a utilização dos serviços, condições socioeconômicas da família e condições bucais como cárie e doença periodontal. Foi realizada uma análise descritiva dos dados coletados e apresentados em formato de tabela de frequência e porcentagem.

\section{Palavras-chave:}

saúde bucal, adultos, epidemiologia

\section{Introdução}

Os levantamentos epidemiológicos possibilitam identificar as necessidades, as condições de saúde e doença da população permitindo quantificá-las e servir para o planejamento e organização dos serviços de saúde bucal. $\mathrm{O}$ atual estudo utilizou os dados da população adulta (33-44 anos) do levantamento epidemiológico de base domiciliar das condições orais no Estado de São Paulo (SB SP 2015) para verificar a prevalência de condições socioeconômicas e bucais como cárie e envolvimento periodontal e utilização dos serviços odontológicos na população de adultos.

\section{Resultados e Discussão}

$\mathrm{Na}$ tabela 1, com relação à utilização do serviço a variável mais prevalente foi referente a ida à consulta ao dentista na qual, $5817(96,13 \%)$ indivíduos responderam sim. Nas variáveis de condições bucais as mais prevalentes foram 4595 (75,94\%) pessoas apresentaram igual a 0 número de dentes obturados com cárie e índice de CPO-D mais que 16 de 5193 (85,82\%) pessoas. No bloco socioeconômico tem-se a variável mais prevalente foi número de pessoas residentes na casa menor ou igual a 4 pessoas residentes igual a $4186(69,18 \%)$ de pessoas. $\mathrm{Na}$ história da saúde bucal tem-se que o atendimento odontológico era de caráter curativo, resultando muitas vezes em exodontias ${ }^{1}$. Esse fato levou à uma população que busca pelo atendimento apenas em situações de dor, em situações críticas e um alto índice de edentulismo, restaurações e obturações. Foi observado em uma avaliação à nível nacional ${ }^{2}$ que o menor acesso ao serviço odontológico com o passar da idade foi maior no grupo de baixa condição socioeconômica, pois com o avanço da mesma a oportunidade de acesso ao sistema público reduz 3 .

\section{Agradecimentos}

Ao Conselho Nacional de Desenvolvimento Científico e Tecnológico $(\mathrm{CNPq})$, pela concessão da bolsa de Iniciação Científica.

1. MOREIRA RS, NICO LS, Tomita NE, RUIZ T. A saúde bucal do idoso brasileiro: revisão sistemática sobre o quadro epidemiológico e acesso aos serviços de saúde bucal.

Cad Saude Publica. 2005;21(6):1665-75.

2.BARROS AJD., BERTOLDI AD. Desigualdades na utilização e no acesso a serviços odontológicos: uma avaliação em nível nacional. Ciênc. saúde coletiva [online]. 2002, vol.7, n.4, pp.709-717. ISSN 1413-8123 avaliação em nivel nacional. Ciênc. saúde coletiva [online]. 2002, vol.7, n.4, pp.709-717. ISSN 1413-8123 populacional dos fatores associados com o uso regular de serviços odontológicos em adultos. Cadernos de Saúde Pública. 2001, 17(3):661-668.
Tabela 1. Frequência e porcentagem das variáveis estudadas em adultos entre 33-44 anos

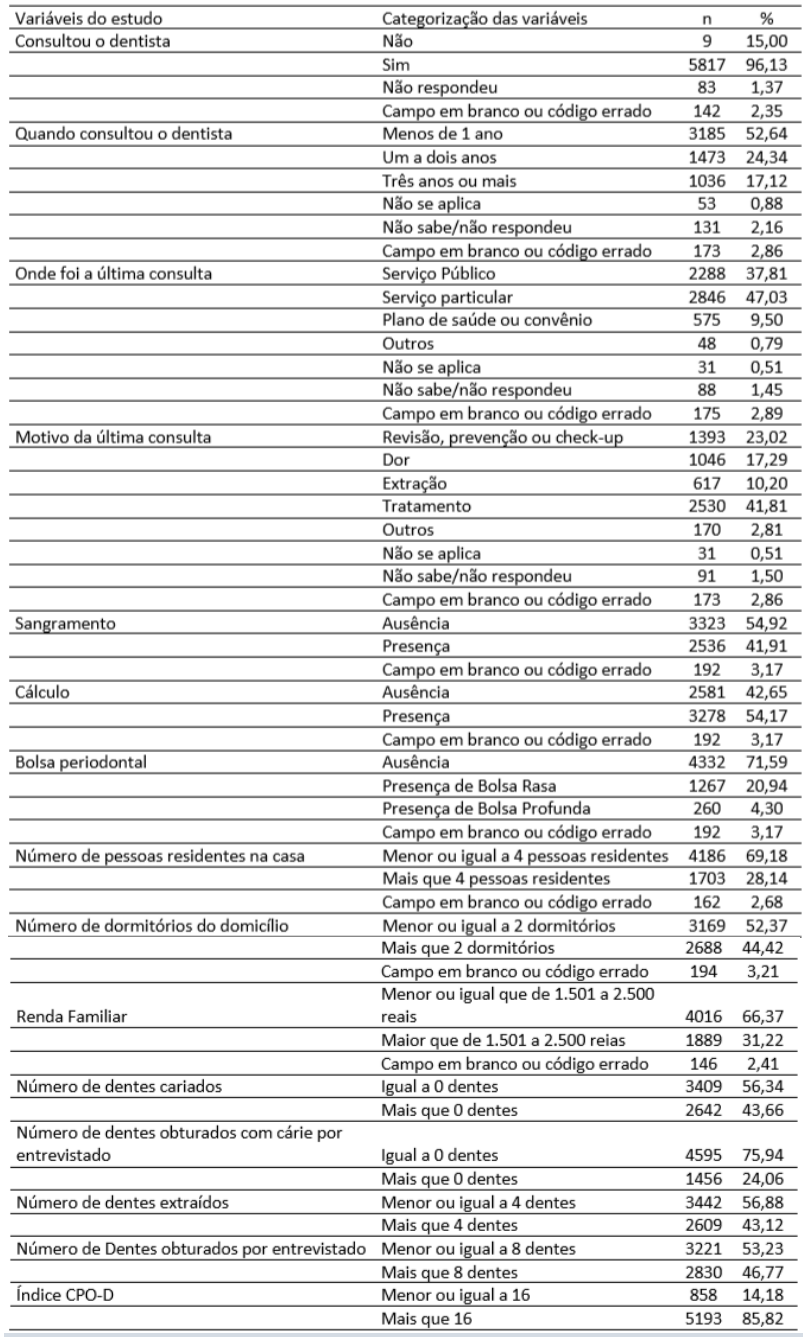

\section{Conclusões}

As variáveis com os dados mais prevalentes foram consulta ao dentista; índice de CPO-D maior que 16, ausência de número de dentes obturados com cárie e menor ou igual a 4 pessoas residentes na casa. 